\title{
Correction to: The Impact of Psychological Capital and Occupational Stress on Teacher Burnout: Mediating Role of Coping Styles
}

\author{
Ye Zhang $^{1} \cdot$ Shanshan Zhang $^{1} \cdot$ Weiyan Hua ${ }^{1}$
}

Published online: 29 June 2019

(C) De La Salle University 2019

\section{Correction to: Asia-Pacific Edu Res}

https://doi.org/10.1007/s40299-019-00446-4

In the original published article, Table 1 and Fig. 1 were published incorrectly. The correct version (Table 1 and Fig. 1) is provided in this correction.

Table 1 Descriptive statistics and correlation matrix of all variables

\begin{tabular}{|c|c|c|c|c|c|}
\hline Variables & 1 & 2 & 3 & 4 & 5 \\
\hline 1. Psychological capital & - & $-.28 * *$ & $-.21 * *$ & $.58 * *$ & $-.67 * *$ \\
\hline 2. Occupational stress & & - & $.26 * *$ & $-.21 * *$ & $.54 * *$ \\
\hline 3. Negative coping style & & & & .06 & $.40 * *$ \\
\hline 4. Positive coping style & & & & - & $-.41 * *$ \\
\hline 5. Teacher burnout & & & & & - \\
\hline Mean & 122.04 & 134.85 & 18.01 & 34.76 & 58.85 \\
\hline SD & 23.91 & 33.84 & 4.57 & 5.91 & 14.04 \\
\hline Skewness & -.21 & -.10 & -.05 & .38 & -.30 \\
\hline Kurtosis & -.25 & -.54 & .21 & .05 & -.04 \\
\hline
\end{tabular}

$S D$ standard deviations

$* * p<.01$

The original article can be found online at https://doi.org/10.1007/s40299-019-00446-4.

Shanshan Zhang

zhangxiaobai2@163.com

1 Education Science College, Shenyang Normal University, No. 253, the Yellow River North Street, Shenyang, People's Republic of China 
Fig. 1 The hypothesized

mediating model for the coping style and multi-group model for teaching experience

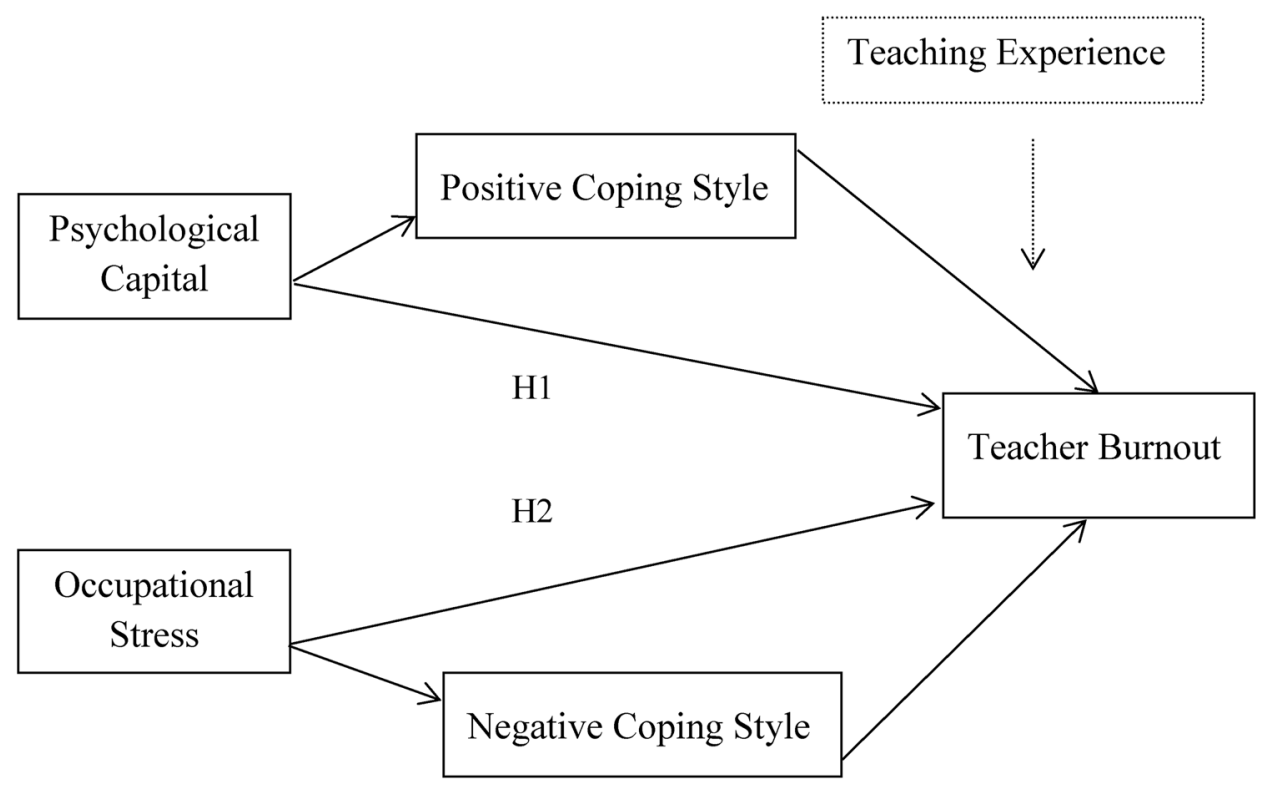

Publisher's Note Springer Nature remains neutral with regard to jurisdictional claims in published maps and institutional affiliations. 